\title{
Pasture yield mapping: why \& how
}

\author{
S.J. DENNIS ${ }^{1}$, A.L. TAYLOR ${ }^{2}$, K. O’NEILL ${ }^{3}$, W. CLARKE-HILL ${ }^{2}$, R.A. DYNES ${ }^{2}$, \\ N. COX ${ }^{3}$, C. van KOTEN ${ }^{2}$ and T.W.D. JOWETT ${ }^{4}$ \\ ${ }^{1}$ Grounded, Hardys Rd, RD1, Coalgate \\ ${ }^{2}$ AgResearch, Lincoln Research Centre, Private Bag 4749, Christchurch \\ ${ }^{3}$ AgResearch, Invermay, Private Bag 50034, Mosgiel \\ ${ }^{4}$ University of Otago, P.O. Box 56, Dunedin
}

Samuel@grounded.co.nz

\begin{abstract}
Spatial variation in pasture yield within a single paddock can be high. Measuring this variation has many potential benefits. For instance, cost-effective targeted treatments could be applied to low yielding areas resulting in increased pasture yield at a paddock scale with minimal cost. Understanding pasture yield variation requires tools that can measure it, and practical methodologies to guide how and when to use these tools to obtain useful data. The study reported here aimed to develop measurement protocols for using the C-Dax pasture meter to map yields of rotationally grazed pastures. The general principles should be applicable to other measurement tools. The pattern of pasture yield varies throughout the year. Because growing conditions change with the seasons, areas of a paddock that perform well in summer may perform poorly in winter, and vice-versa. Time of year is therefore an important consideration for measurement purposes. The recommended protocol developed from this project to estimate the spatial variation in annual yield on a paddock is to:

- map 1 month following peak pasture growth rates;

- drive at up to $50 \mathrm{~m}$ run spacings, but close enough to cover all features of interest; and

- map as close to the grazing event as possible within the final third of the regrowth period.
\end{abstract}

Keywords: Yield mapping, pasture, precision agriculture, pasture height, dairy, spatial management

\section{Introduction}

Pasture yields are the result of many different factors interacting - species, soils, rainfall, temperature, grazing management, fertility, irrigation etc. Some of these factors are the same over wide areas - such as rainfall and temperature. But most can vary greatly from one area of a paddock to another.

As a result, a paddock can have some areas that produce high yields, and some that produce low yields. Factors limiting yield may differ from one part of a paddock to another. For example, one area may have soils that are stony with limited water holding capacity, while another area may be affected by soil compaction.
Generally pastures are managed uniformly over large areas. Fertiliser is prescribed to multiple paddocks based on a single soil test, or at best is prescribed on a per-paddock basis, and applied uniformly to the entire paddock. Irrigators cover very large areas with the same application rate from a single machine. Pasture renewal occurs over an entire paddock, with a single species mixture used everywhere.

There may be opportunities to improve yields further, and increase efficiency, by understanding the variation within a paddock. For instance, by identifying the lowest yielding areas of a paddock, determining the factors limiting yield and correcting these, total paddock yield can be improved as a result. This may be more cost-effective than treating the entire paddock. Conversely, identification of the highest yielding areas may allow the identification of methods to further increase yields on these areas. In order to assess the importance of the within-paddock variation in pasture yield a method for mapping pasture yield is required.

Variation in crop yield within a paddock has received considerable research attention, and is already used by some farmers to define management zones, for instance for variable rate fertiliser (Stafford et al. 1996; Godwin et al. 2003; Robertson et al. 2007). Many of the techniques that have been developed for the arable sector may be applicable to pastures, if a suitable method of assessing yield variation can be developed.

The aim of the study reported in this paper was to develop a methodology for mapping the yield of rotationally grazed pastures using equipment that is already commercially available. The C-Dax pasture meter is capable of yield mapping pastures (McVeagh et al. 2012), but there are no guidelines available on when and how to map. The wider project developed yield mapping methods, applied these to farms, and investigated the causes of yield variation. This paper presents only the yield mapping methodology.

Pasture yield mapping was not considered as a substitute for pasture cover data collection during weekly farm walks. Yield mapping with current tools is more time consuming and may not be practical to conduct regularly. Yield mapping is investigated as an additional measurement that could be conducted 
at strategic times to guide specific operations. Weekly farm walks give current covers and per-paddock production. Yield mapping could complement this by giving information on within-paddock yield variation.

\section{Methods}

The pattern of pasture mass on a paddock can change throughout the year, and there are practical restrictions to when pasture height could be actually mapped onfarm given staffing resources. This study aimed to answer the following questions to determine a practical yield mapping protocol:

1. when during the year should mapping occur?

2. how close to grazing must mapping occur? Although immediately pre-grazing is ideal, this is unlikely to be practical in all circumstances, so how many days before grazing can a paddock be mapped while still giving usable data?

3. what pattern must be driven within the paddock, i.e., how closely must runs be spaced?

4. must the same runs be followed every time the paddock is mapped?

Six paddocks were selected at the Lincoln University Dairy Farm (LUDF) to represent a range of soil types. Each of these paddocks was mapped pre- and postgrazing at almost every grazing event for 2 years (approximately 14\% of mapping events were missed for practical reasons), from September 2012 to October 2014. Data were collected within 3 days of the grazing event, as close to grazing as practical.

Pasture height was mapped using a C-Dax pasture meter. Each paddock was mapped in the same way. The pasture meter was driven around the edge of the paddock, then in parallel runs approximately $12.5 \mathrm{~m}$ apart over the remainder of the paddock. Pasture height was measured continuously, and the average height was logged each second along with the associated GPS location of the machine. At the maximum recommended operating speed of $5 \mathrm{~m}$ per second, each measurement represented the average pasture height of a $5 \mathrm{~m}$ long strip of pasture, and the location represented the end of that strip (not the centre). As the machine was operated at a variable speed depending on ground conditions but always below the maximum recommended operating speed, measurements in practice were less than $5 \mathrm{~m}$ apart. It took approximately 40 minutes to map an 8 ha paddock at $12.5 \mathrm{~m}$ run spacings.

The pasture height data were downloaded to a computer, and loaded into GIS software (ArcGIS and QGIS for illustrations, or R for statistical analysis) (ESRI 2011; QGIS Development Team 2015; R Core Team 2015) to create a raster map of pasture height. This map was converted to pasture cover in $\mathrm{kg} \mathrm{DM} /$ ha using the recommended equation for Canterbury ( $\mathrm{kg}$ $\mathrm{DM} / \mathrm{ha}=(\mathrm{mm} \times 18.1)+729)(\mathrm{C}-\mathrm{Dax} 2014)$.

\section{Data analysis}

\section{Optimal timing during the year}

It was assumed that the most valuable map for a farmer would represent the variation in total annual consumed pasture. However, it was also assumed that it would be impractical to map pasture height every grazing to determine this, therefore an optimal single time of year needed to be identified when a map of pre-grazing pasture height would most closely reflect the variation in total annual consumed pasture. In other words, a time of year when areas that were low-yielding on an annual basis had low growth rates and therefore low pre-grazing pasture covers, and areas that were highyielding annually had high covers.

The optimal time of year to map in order to obtain a single estimate of annual yield variation was determined by comparing the variation in each pre-grazing pasture height map with the variation in annual consumed pasture, using rank correlation. The cells in each map were ranked from lowest to highest yield and compared statistically to determine whether the lowest yielding areas in the pre-grazing map were the same as the lowestyielding areas in the annual map (Dennis et al. 2014).

\section{Timing relative to grazing.}

It was assumed that shorter intervals between mapping and grazing would produce more reliable results. However practical considerations will often necessitate mapping several days prior to grazing if multiple paddocks are to be mapped on one day. To determine how close to grazing a paddock must be mapped, several paddocks were mapped every 3 days from immediately post-grazing to immediately prior to the next grazing event. It was assumed that the final pre-grazing map was definitive, and the previous maps were compared to this one to determine how well earlier maps represented the final variation.

\section{Run spacing}

Data from individual paddocks mapped at approximately $12.5 \mathrm{~m}$ run spacings were converted to raster maps with $50 \times 50 \mathrm{~m}$ grid squares using either all data, or subsets of the data to generate maps at 25 and $50 \mathrm{~m}$ run spacings. These maps were compared to determine the mean absolute difference in the pasture cover obtained from the $12.5 \mathrm{~m}$ run spacing map (taken to be the definitive map), and the maps collected at wider run spacings.

\section{Repeating the same run patterns}

Subsets at $25 \mathrm{~m}$ run spacings were also produced using every even-numbered or every odd-numbered run, and compared in the same way, to determine how much error was introduced by driving along different tracks in the same paddock. 


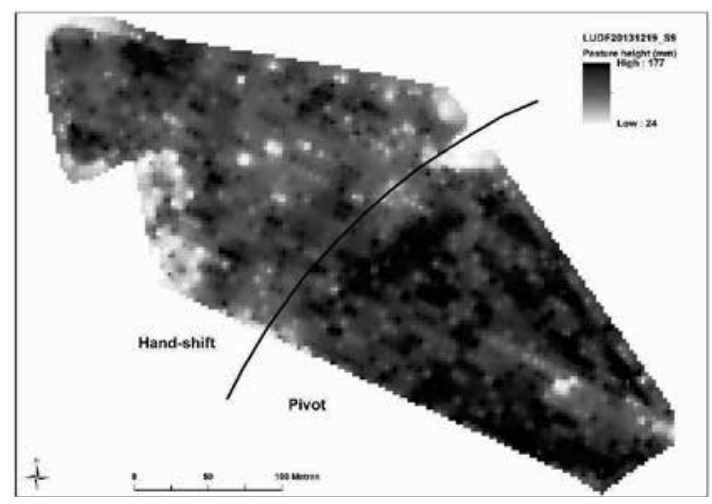

Figure 1 Pre-grazing pasture height measured in paddock S9 at Lincoln University Dairy Farm in December 2013 The right-hand half of the paddock was irrigated by a centre pivot, while the left-hand half was irrigated with a hand-shift system.

\section{Results and discussion}

Wide ranges in pasture cover were observed within individual paddocks. Figure 1 represents a typical pasture height map. In this case, pasture height ranges from $30-175 \mathrm{~mm}$, and pasture cover ranges from 1300 to $3900 \mathrm{~kg} \mathrm{DM} / \mathrm{ha}$. If grazed to a residual of $1500 \mathrm{~kg}$ $\mathrm{DM} / \mathrm{ha}$, available feed ranges from 0 to $2400 \mathrm{~kg} \mathrm{DM} /$ ha. For the paddock depicted in Figure 1, half of the paddock was irrigated by a centre pivot, while the other half was irrigated with a hand-shift system. The area irrigated by the centre pivot had higher and more spatially-uniform yields than the area irrigated by the hand-shift system.

\section{Optimal timing during the year}

The pattern of variation differed from one time of year to another. In some cases, areas of a paddock that had high yields in spring were among the lowest yielding in summer (Figures 1,2). Although the actual pattern of variation was paddock-specific, it was common to see large differences in variation measured on the same paddock in spring versus summer. For instance, for the paddock depicted in Figures 1 and 2, in spring the highest yields occurred on the hand-shift irrigated half while in summer the pivot-irrigated half was higher yielding.

In general, the largest variations in pasture yield observed were clearly correlated with factors affecting plant available water: irrigation (as in Figure 1), topography or soil water holding capacity. However water tends to be a limiting factor for yield in summer, but not in winter or early spring. Areas that suffered water shortages in summer may have sufficient water in winter and yield well, while areas that had sufficient water in summer may be waterlogged in winter and yield poorly. This results in large differences in the

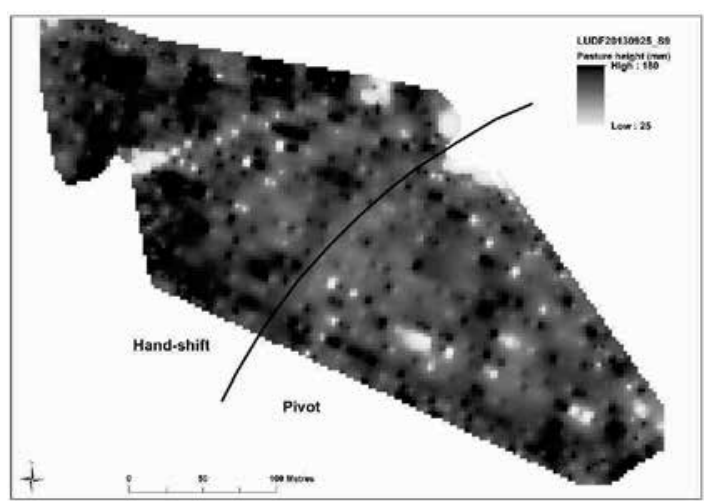

Figure 2 Pre-grazing pasture height measured in paddock S9 at Lincoln University Dairy Farm in September 2013. The right-hand half of the paddock was irrigated by a centre pivot, while the left-hand half was irrigated with a hand-shift system.

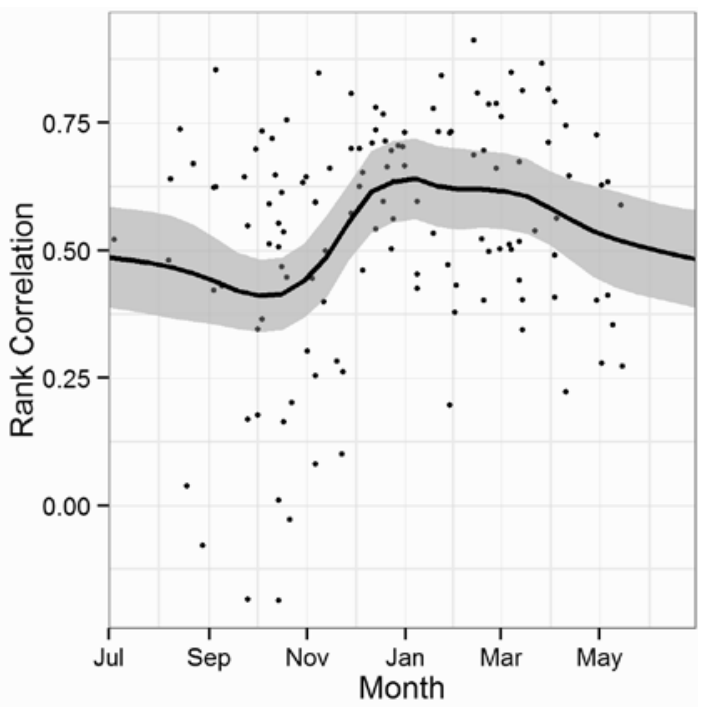

Figure 3 Rank correlation between pre-grazing pasture height and annual consumed pasture. Line = smoothed means (LOESS smoothing algorithm, $\mathrm{a}=0.2$, grey band $=\mathrm{SE}$ ). Points $=$ individual maps, all maps collected on LUDF over two years.

pattern of yield observed at different times of the year, and sometimes complete reversals with the highest yielding areas at one time of the year being the lowest yielding at another. Timing of mapping through the year was critical for obtaining meaningful data.

The correlation between seasonal pre-grazing pasture height and annual consumed pasture is presented in Figure 3. The highest consistent correlation was observed in December, with correlations remaining generally high throughout the summer months. Maps produced from data collected in spring were inconsistent, and did not correlate strongly with annual yields. 


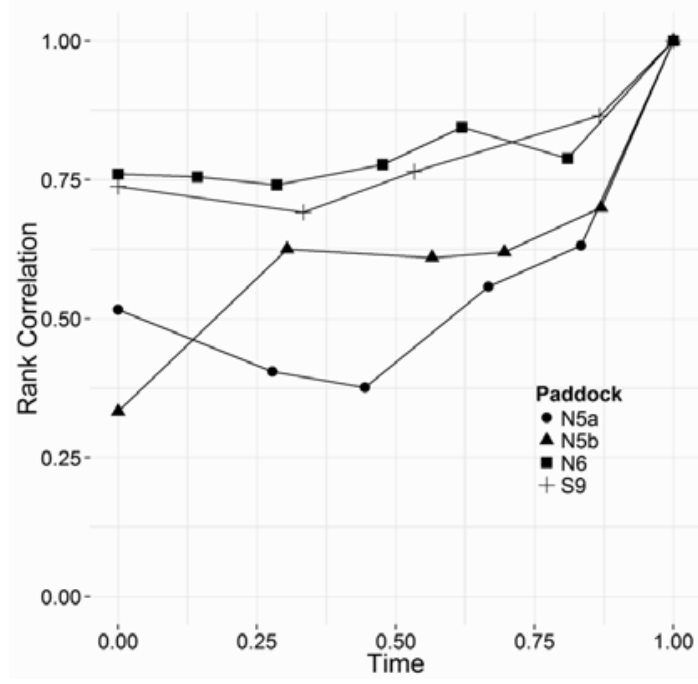

Figure 4 Rank correlation between pasture height during the regrowth period and final pre-grazing pasture height. Time 0 = post-grazing, 1 = final pre-grazing map. Higher "Rank Correlation" values = pattern of variation more similar to the pattern in the pregrazing map. Data $=$ four series of repeated maps on paddocks at LUDF, summer 2012/13.

For LUDF, mapping in December gave the best estimate of mean annual pasture yield variation, or failing that any time in summer gave a reasonable estimate of variation. For this farm, pasture yield generally peaks in November/December and then remains high through summer, with some variation between years, so these months are responsible for a high proportion of total annual yield and will drive annual yield variation. Also, the main driver of yield variation on this property is the irrigation system (Figure 1), the effect of which is most visible in summer. On an unirrigated property pasture growth rates would be expected to peak earlier, with late spring yield having a higher influence on annual yield variation, so the optimal time to map may be earlier than on this property. Until further data are collected to verify the optimal timing under other conditions, mapping should be conducted one month after peak pasture growth rates are reached, or as close to this as is practical.

\section{Timing relative to grazing}

The correlation between pasture height measured at different intervals between grazings and heights recorded on the final occasion before grazing is presented in Figure 4. Rank correlations tended to improve in the last third of the regrowth period. However on a visual comparison of the maps, the areas of highest and lowest yield were visible from even earlier.

High yielding areas appeared to have the highest growth rates from immediately following grazing. This meant that higher or lower yielding areas became visible some time before grazing. Although mapping should obviously occur as close to grazing as possible, if the aim is simply to identify relatively high or low yielding areas, mapping can occur any time in the final third of the regrowth period, or possibly even earlier if necessary.

\section{Run spacing}

The mean and maximum absolute differences between pasture yield recorded at 25 and $50 \mathrm{~m}$ run spacings compared with $12.5 \mathrm{~m}$ spacings are presented in Table 1. When using wider run spacings, any individual point only differed by an average of 49 or $89 \mathrm{~kg} \mathrm{DM} / \mathrm{ha}$ from the measurement that would have been obtained using $12.5 \mathrm{~m}$ run spacings, although a small number of points could differ by several hundred $\mathrm{kg} \mathrm{DM} / \mathrm{ha}$. The error introduced by the wider run spacings was minimal, and generally well below the estimated $500 \mathrm{~kg} \mathrm{DM} /$ ha margin of error of the C-Dax sensor (Rennie et al. 2009).

Mapping at up to $50 \mathrm{~m}$ run spacings was acceptable and did not introduce excessive error. However if there are narrow features in a paddock that could be either over- or under-represented at such a wide run spacing, a narrower spacing will need to be used to capture them accurately.

\section{Repeating the same run pattern}

The error introduced by driving two different sets of $25 \mathrm{~m}$ run spacings in a single paddock is presented in Table 2. Two separate sets of runs in the same paddock estimated pasture mass at any point to within $65 \mathrm{~kg}$

Table 1 Error introduced by mapping at 25 or $50 \mathrm{~m}$ run spacings, on 6 paddocks. Values are mean and maximum absolute deviation from the pasture mass measured in any $50 \times 50 \mathrm{~m}$ grid cell using a more detailed map (12.5 m run spacings). Replicates each represent a set of measurements on one paddock on a single day. Paddock and date differs between reps.

\begin{tabular}{lccccc}
\hline \multirow{2}{*}{ Replicate } & \multicolumn{2}{c}{$25 \mathrm{~m}$} & & \multicolumn{2}{c}{$50 \mathrm{~m}$} \\
\cline { 2 - 3 } \cline { 6 - 6 } \cline { 5 - 6 } A & Mean & Max & & Mean & Max \\
\hline B & 28 & 123 & & 68 & 195 \\
C & 64 & 651 & & 89 & 724 \\
D & 31 & 261 & & 61 & 430 \\
E & 53 & 522 & & 113 & 827 \\
F & 62 & 258 & & 94 & 568 \\
\hline Overall Mean / Max & 49 & 651 & & 89 & 827 \\
\hline
\end{tabular}


$\mathrm{DM} / \mathrm{ha}$ of each other on average. This again is well below the C-Dax margin of error. Using two different sets of runs offset from each other resulted in essentially identical maps. Provided the run spacings are narrow enough to represent all major features in the paddock there is no need to drive in the same runs every time.

\section{Limitations and application}

Pasture yield mapping only measures yield variation; it does not explain that variation. It has potential to be the first step to assess many different issues. For instance, yield mapping could be used to not only identify the most variable paddocks on a farm for pasture renewal, but also identify the poorest yielding areas of those paddocks for further investigation, so the causes of their poor yields can be identified and corrected if possible to ensure the same issues do not reappear in the new pasture. It may also be used to assess irrigation systems, waterlogging, fenceline placement on a new conversion, fertiliser recommendations, or for research and education purposes.

There is a need for industry-friendly software to produce yield maps. At present maps can only be produced with specialist GIS software, likely limiting yield mapping to specialist consultants with the capability to process the data.

\section{Conclusions}

The average pasture yield in a paddock is the result of the production on each individual part of that paddock. Understanding this spatial variation gives a new view of the farm, and may open new possibilities for efficiently improving yields.

It is possible to produce pasture yield maps using readily available equipment, such as the C-Dax pasture meter. Reliable data may be collected by driving at up to $50 \mathrm{~m}$ run spacings, though narrow enough to capture all features of interest in the last third of the regrowth period. There is no need to use the same tracks every time.

Table 2 Error introduced by mapping at two different sets of $25 \mathrm{~m}$ spaced runs. Values are mean and maximum absolute deviation in any $50 \times 50 \mathrm{~m}$ grid cell between the height measured in two separate sets of parallel runs in the same paddock on the same date.

\begin{tabular}{lcl}
\hline Replicate & Mean & Max \\
\hline A & 43 & 339 \\
B & 64 & 542 \\
C & 89 & 717 \\
\hline Overall Mean / Max & 65 & 717 \\
\hline
\end{tabular}

Yield variation can change markedly between seasons, so the time of year the paddock is mapped is critical. To obtain an overall indication of annual yield variation, irrigated Canterbury dairy farms should be mapped in December, or failing that any time in summer. It is suggested that other farms are mapped approximately one month after reaching peak pasture growth rates, but this needs to be verified in future research.

\section{ACKNOWLEDGEMENTS}

The authors thank participating farmers for their support and cooperation. We also thank SIDDC (Ron Pellow), Lincoln University (Chris Littlejohn) and Carolyn Hedley for their contribution. This project is funded by the New Zealand Ministry of Primary Industries through the Sustainable Farming Fund, New Zealand Dairy Farmers through DairyNZ, and Ravensdown.

\section{REFERENCES}

C-Dax. 2014. Pasture Meter XC1 with Auto Lift. http://www.c-dax.co.nz/index.php?page $=$ shop/ flypage \&product_id=17331\&parent cats $=8$ fb6a98cdda3e6ee46d4a736f8efb89d.

Dennis, S.J.; Clarke-Hill, W.; Taylor, A.L.; Dynes, R.A.; O'Neill, K.; Jowett, T. 2014. Estimating Spatial Variation in Annual Pasture Yield. In: Proceedings of the 12th International Conference on Precision Agriculture. Sacramento, California, USA: International Society of Precision Agriculture. www. ispag.org.

ESRI. 2011. ArcGIS Desktop (version 10). Redlands, California: Environmental Systems Research Institute.

Godwin, R.J.; Wood, G.A.; Taylor, J.C.; Knight, S.M.; Welsh, J.P. 2003. Precision farming of cereal crops: a review of a six year experiment to develop management guidelines. Biosystems Engineering 84: 375-91. doi:10.1016/S1537-5110(03)00031-X.

McVeagh, P.; Yule, I.J.; Grafton, M. 2012. Pasture yield mapping from your groundspread truck. In: Advanced Nutrient Management: Gains from the Past - Goals for the Future. Eds. Currie, L.D.; Christensen, C.L. Occasional Report No. 25. Fertilizer and Lime Research Centre. Massey University. http://www. massey.ac.nz/ flrc/workshops/12/Manuscripts/ McVeagh_2012.pdf

QGIS Development Team. 2015. Quantum GIS (version 2.6.1). Open Source Geospatial Foundation Project. http://qgis.osgeo.org.

R Core Team. 2015. R: A Language and Environment for Statistical Computing (version 3.1.2). Vienna, Austria: R Foundation for Statistical Computing. http://www.R-project.org. 
Rennie, G.M.; Puha, M.R.; Dalley, D.E.; Dynes, R.A.; Upsdell, M.P. 2009. Calibration of the C-DAX Rapid Pasturemeter and the Rising Plate Meter for kikuyu-based northland dairy pastures." Proceedings of the New Zealand Grassland Association 71: 49-55.

Robertson, M.; Isbister, B.; Maling, I.; Oliver, Y.; Wong, M.; Adams, M.; Bowden,B.; Tozer, P. 2007.
Opportunities and constraints for managing withinfield spatial variability in Western Australian grain production. Field Crops Research 104: 60-67. doi:10.1016/j.fcr.2006.12.013.

Stafford, J.V.; Ambler, B.; Lark, R. M.; Catt, J. 1996. Mapping and interpreting the yield variation in cereal crops. Computers and Electronics in Agriculture 14: 101-19. doi:10.1016/0168-1699(95)00042-9. 